\title{
Comunicação
}

[Communication]

\section{Mastite clinica caprina causada por Arcanobacterium pyogenes}

[Clinical mastitis in goat due to Arcanobacterium pyogenes]

\author{
F. Garino Jr. ${ }^{1}$, R.A.T. Matos $^{2}$, E.G. Miranda Neto ${ }^{1}$, J.N.N. Bernardino ${ }^{3}$, \\ E.D. Santos ${ }^{1}$, G.M.N. Aguiar ${ }^{1}$
}

${ }^{1}$ Universidade Federal de Campina Grande/CSTR/Campus de Patos, PB
${ }^{2}$ Aluno de pós-graduação - Universidade Federal de Campina Grande/CSTR/Campus de Patos, PB

${ }^{3}$ Médico veterinário autônomo

\begin{abstract}
Arcanobacterium pyogenes é uma bactéria pertencente à família Actinomycetaceae, Gram positiva, com morfologia de bastonetes pleomórficos. Tem como habitat natural as superfícies mucosas, principalmente da cavidade oral, nasofaringe, sistema urogenital e trato gastrointestinal de animais. As infecções por este micro-organismo são geralmente endógenas e na maioria das espécies provocam abscessos nos tecidos. Em bovinos, ovinos e caprinos pode causar mastite crônica ou aguda, pneumonia supurativa, artrite séptica, endocardite vegetativa, endometrite, sinusite crônica, infecções umbilicais, vesiculite seminal e infecções secundárias em ferimentos (Jost e Billington, 2005).
\end{abstract}

Em bovinos, A. pyogenes foi diagnosticado como causa de mastite em novilhas, vacas leiteiras e vacas de corte, além de endometrite, abscesso hepático, abscessos do sistema nervoso e doença do sistema respiratório. (Costa et al., 2000; Seifi et al., 2003; Domingues et al., 2008). Tem sido apontado como patógeno de menor importância em casos de mastite clínica em pequenos ruminantes (Bergonier, et al., 2003).

Segundo Berry (1998), a mastite causada por $A$. pyogenes é caracterizada por apresentar-se na forma aguda, com tendência à cronicidade. A doença pode evoluir passando a apresentar secreção purulenta da glândula mamária, odor desagradável e fistulação da pele. Em casos severos pode ocorrer a perda funcional ou até mesmo a morte do animal. Foi objetivo deste trabalho, relatar um caso de mastite clinica por Arcanobacterium pyogenes em um cabra no Estado da Paraíba.

Foi encaminhada ao setor de Clínica Médica de Grandes Animais do Hospital Veterinário do Centro de Saúde e Tecnologia Rural (CSTR) da Universidade Federal de Campina Grande (UFCG), Campus de Patos - PB, uma cabra SRD, com três anos de idade com um quadro clínico de mastite. Foi informado que o animal havia perdido peso e cessado a produção de leite após o aparecimento de mamite e de vários abcessos no úbere nos últimos 30 dias. Ao exame clínico foi observado que o animal estava ativo, com apetite presente, mucosas rosadas e parâmetros fisiológicos inalterados. Entretanto, a glândula mamária direita apresentava aumento de volume, temperatura elevada e consistência firme, com abscessos drenando secreção purulenta de odor desagradável (Fig. 1A). A glândula mamária esquerda não produzia secreção (afuncional). Foi coletada amostra de secreção da glândula mamária em frasco estéril e encaminhada ao Laboratório de Microbiologia - do Hospital Veterinário/CSTR/UFCG/Campus de Patos, PB. 


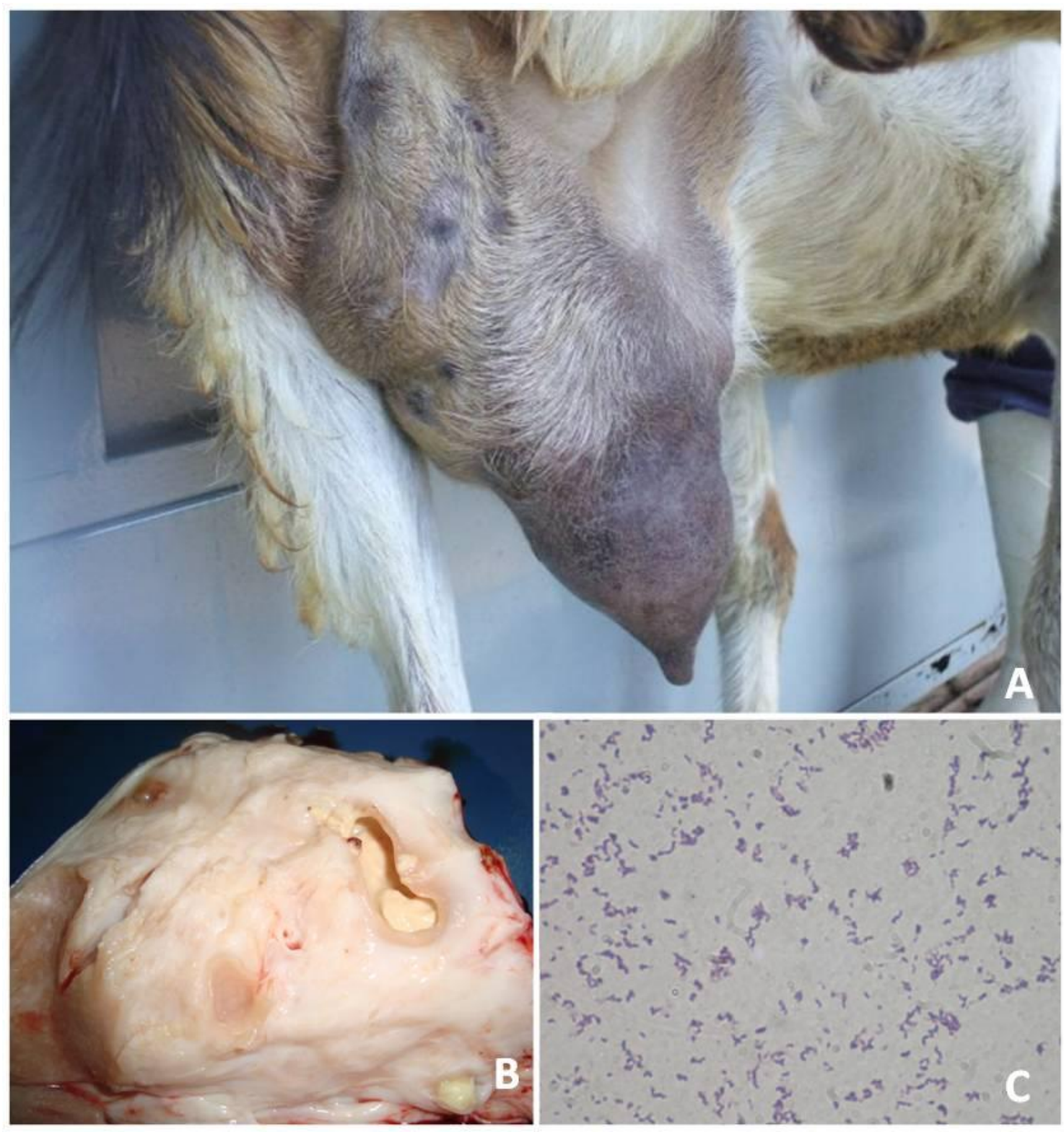

Figura 1. (A) assimetria da glândula mamária; (B) presença de vários abscessos e áreas de fibrose na glândula mamária; (C) fotomicrografia bastonetes pequenos, pleomórficos Gram positivos (1000x).

A amostra foi semeada em agar sangue, agar MacConkey (HIMEDIA - Mumbai - Índia), incubada a $37^{\circ} \mathrm{C}$ em aerobiose, sendo realizada leitura após 48h. No exame macroscópico apresentou cultura pura, colônias minúsculas transparentes com presença de $\beta$ - hemólise. Ao exame microscópico pela técnica de coloração de Gram, observaram-se micro-organismos Gram positivos, corineformes e pleomórficos. De acordo com os resultados dos testes bioquímicos: redução de nitrato, gelatinase, camp teste, glicose e xilose positivos; maltose, sacarose, manitol e catalase negativos. $\mathrm{O}$ microorganismo foi identificado como Arcanobacterium pyogenes (Rodloff et al., 1999).

No Brasil, Domingues et al. (2008), relatou um caso de mastite por $A$. pyogenes em uma novilha da raça Holandesa de 4 meses de idade. Costa et al. (2000), verificou um surto de mastite por esse microorganismo em gado de corte no Estado de São Paulo. Motta et al. (2011), verificou um 
surto de mastite bovina por A. pyogenes no Estado de São Paulo. Em pequenos ruminantes, no Brasil, há poucos estudos relatos de casos de mastite por esse micro-organismo. Este fato pode ser devido a sua baixa incidência, ou mesmo a doença pode estar sendo subdiagnosticada.

Estudo realizado por Mørk, et al. (2007) avaliando a etiologia de 547 glândulas mamárias de ovelhas com mastite clinica na Noruega, verificou $0,7 \%$ de incidência, demonstrando a baixa incidência de mastite por este microorganismo. Lucheis et al. (2010), em estudo realizado sobre a etiologia da mastite ovina na região de Bauru, SP, verificou a ocorrência de mastite por A. pyogenes $5(2,8 \%)$ das 309 amostras de leite avaliadas. O controle desta enfermidade é realizado através de medidas sanitárias e inspeção dos animais, uma vez que o A. pyogenes pode estar presente no ambiente $\mathrm{e}$ ser transmitido por insetos (moscas) (Berry, 1998). O tratamento recomendado é o uso associado de antibioticoterapia parenteral e intramamário, porém quando o animal é diagnosticado, geralmente está na forma aguda e o tratamento pode ser ineficaz com a possibilidade da perda de função da glândula mamária acometida. No animal deste relato de caso não foi realizado antibioticoterapia, pois o animal apresentava comprometimento da glândula mamária. Como resolução clínica foi realizada a mastectomia total, sendo recomendadas ao produtor, medidas profiláticas com a finalidade de evitar o contágio de outros animais visto que o mesmo retornou para o rebanho.

Palavras-chave: mastite clinica, caprina, Arcanobacterium pyogenes

\section{ABSTRACT}

This paper reports the occurrence of goat mastitis due to Arcanobacterium pyogenes in Paraiba State Brazil. The diagnosis was confirmed by clinical symptoms and microbiological culture. A mastectomy was performed as clinical treatment.

Keywords: clinical mastitis, goat, Arcanobacterium pyogenes

\section{REFERÊNCIAS}

BERGONIER, D.; CRÉMOUX, R.; RUPP, R. et al. Mastitis of dairy small ruminants. Vet. Res. v.34, p.689-716. 2003. Disponível em: <http://www. evsrl.it/vet.journal/archivio_pdf/2007/2311.pdf.>.

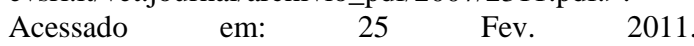
DOI:10.1051/vetres:2003030.

BERRY, E. Update on summer mastitis. Proceedings: the British Mastitis Conference 1998. Axient/Institute for Animal Health, Milk Development Council/Novartis Animal Health, 1998. p.46-53.

COSTA, E.O.; RIBEIRO, A.R.; WATANABE, E.T.; SILVA, J.A.B. Mastite por Arcanobacterium pyogenes: surto em rebanho de gado de corte. Núcleo Apoio Pesq. Gland. Mamária Prod. Leiteira, v.1, p.08-12, 2000.

DOMINGUES, P.F.; FERREIRA, B.L.S.; GALDINO, M.C. et al. Mastite em bezerra por Arcanobacterium pyogenes: relato de caso. Vet. Zootec, v.15, p.257-262, 2008. Disponível em: <Http://www.fmvZ.unesp.br/revista/volumes/vol15_n2 /VZ15_2(2008)_257-262.pdf $>$. Acessado em: 25 de Fev. 2011.
JOST, B.H.; BILLINGTON, S.J. Arcanobacterium pyogenes: molecular pathogenesis of an animal opportunist, Antonie van Leeuwenhoek, v.88, p.87102, 2005. Disponível em: $<\mathrm{http} / / / w w w . m i c r o v e t . a r i z o n a . e d u / F a c u l t y / j o s t / P D F s / a$ preview.pdf>, Acessado em: 05 Mar. 2011. DOI 10.1007/s10482-005-2316-5.

LUCHEIS S.B.; HERNANDEZ, G.S.; TRONCARELLI, M.Z. Monitoramento microbiológico da mastite ovina na região de Bauru, SP. Arq. Inst. Biol., v.77, p.395403, 2010.

MØRK T.; WAAGE S.; TOLLERSRUD T. et al. Clinical mastitis in ewes; bacteriology, epidemiology and clinical features. Acta Vet. Scand., v.49, p.23, 2007. Disponível em <http://www.actavetscand.com/content/49/1/23>.

Acessado em: 25 Fev. 2011.

MOTTA, R.G.; RIBEIRO, M.G.; PERROTTI, I.B.M. et al. Surto de mastite bovina causada por Arcanobacterium pyogenes. Arq. Bras. Med. Vet. Zootec., v.63, p.736-740, 2011. 
RODLOFF, A.C.; HILLIER, S.L.; MONCLA, B.J. Peptostreptococcus, Propionibacterium, Lactobacillus, Actinomyces, and other non-spore-form-forming anaerobic gram-positive bacteria. In: MURRAY, P.R.; BARON, E.J.; PFALLER, M.A. et al. Manual of Clinical Microbiology, 7.ed., Washington: American Society for Microbiology, 1999. p.672-689.
SEIFI, H.A.; SAIFZADEH, S.; FARSHID, A.A. et al. Mandibular pyogranulomatous osteomyelitis in a Sannen goat. J. Vet. Med. Assoc., Physiol. Pathol., Clin. Med. v.50, p.219-21, 2003. Disponível em: http://onlinelibrary.wiley.com/doi/10.1046/j.1439 0442.2003.00520.x/abstract>. Acessado em: 25 Fev. 2011. DOI: 10.1046/j.1439-0442.2003.00520. 